\title{
Sub-monolayer quantum dot quantum cascade mid-infrared photodetector
}

\author{
Jian Huang, ${ }^{1, a)}$ Daqian Guo, ${ }^{2}$, a) Wei Chen, ${ }^{1}$ Zhuo Deng, ${ }^{1}$ Yinghao Bai, ${ }^{1}$ Tinghui \\ Wu, ${ }^{1}$ Yaojiang Chen, ${ }^{1}$ Huiyun Liu $^{2}$, Jiang Wu ${ }^{2}$ b), Baile Chen ${ }^{1, b)}$

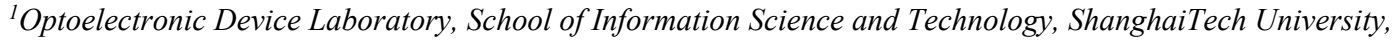 \\ Shanghai 201203, China \\ ${ }^{2}$ Department of Electronic and Electrical Engineering, University College London, London WC1E 7JE, United \\ Kingdom
}

In this work, we demonstrate a sub-monolayer quantum dot quantum cascade photodetector (SML QD-QCD) grown on GaAs for photovoltaic mid-infrared photo-detection. The detector shows normal-incident peak responsivity of $1.90 \mathrm{~mA} / \mathrm{W}$ at the wavelength of $6.05 \mu \mathrm{m}$ and a resistance-area product of $1.54 \times 10^{8} \Omega \cdot \mathrm{cm}^{2}$ at $77 \mathrm{~K}$. The corresponding specific detectivity is $3.22 \times 10^{11} \mathrm{~cm} \cdot \mathrm{Hz}^{1 / 2} / \mathrm{W}$.

Quantum cascade photodetector (QCD) has recently attracted substantial interests due to the advantage that no external bias voltage is required for operation, which leads to zero dark current, much lower noise, relatively high operating temperature, and low power dissipation ${ }^{1}$. Quantum cascade photodetectors based on quantum well (QW-QCDs) have been demonstrated in short infrared wavelength ${ }^{2}$, mid infrared wavelength ${ }^{3}{ }^{4}$ and long infrared wavelength ranges ${ }^{5}$. However, for QW-QCDs, there is no intrinsic response to normal incidence light, due to the inter-subband transition selection rules of quantum wells. Plasmonic waveguides ${ }^{6}$, grating ${ }^{7}$, and photonic crystal slab ${ }^{8}$ have been used to make the QW-QCD sensitive to normal incident light. Quantum dot infrared photodetectors (QDIP) have been extensively studied due to the advantages of three dimensional confinement of carriers, which is expect to have lower dark current, long excited state lifetime and intrinsic sensitivity to normal incident light ${ }^{9}$. In order to achieve normal incidence intra-band response in QCD, the quantum well layer used for light absorption is replaced by quantum dots, which is very similar to the case of quantum well infrared photodetector versus quantum dot infrared photodetector. Moreover, due to the fact that the carrier capture time in quantum dots is much

\footnotetext{
a) Jian Huang and Daqian Guo contributed equally to this work.

b) Corresponding author: jiang.wu@ucl.ac.uk; chenbl@shanghaitech.edu.cn.
} 
longer than that in the quantum wells ${ }^{10}$, the transport through quantum cascade region is potentially more efficient. Barve et al. reported a GaAs based QD-QCD, with optical response peaks between 5 to $6 \mu \mathrm{m}^{11}$. Recently, Wang et al. reported a QDQCD on InP substrate to enjoy the abundance of semiconductor materials grown on InP substrate ${ }^{12}$. Both of these QD-QCDs have shown normal incident response, and are expected to have low dark noise and improved detectivity, compared with other mid-infrared photodetectors.

In both Barve's and Wang's work, quantum dots are formed by the Stranski-Krastanov (SK) epitaxial growth mode. However, quantum dots based on the SK growth mode usually suffer from the size inhomogeneity in dot structures, low QD density, and reduction of carrier confinement due to the presence of a wetting layer. Sub-monolayer (SML) QD is one of the attractive alternatives to SK-QDs with self-assembly techniques. SML-QDs have several advantages over SK-QDs including better quantum confinement, higher dot areal density and absence of the wetting layer. Typically, InAs SML-QDs consists of a stacked deposition of QD materials with a thickness normally below one monolayer in barrier materials ${ }^{13}$. These SML-QDs have been demonstrated for laser ${ }^{14}$, solar cell ${ }^{15}$, and quantum dot infrared photodetector ${ }^{16}$ applications. Despite the advantages of SML-QDs, photodetectors based on SML-QDs have not been reported so far.

In this paper, we demonstrate the QD-QCD devices which utilize SML InAs QDs for mid-infrared absorption. The structure is based on InGaAs/GaAs/AlGaAs heterostructures grown on a GaAs substrate with the layer schematics shown in Fig 1. The QD-QCD sample was grown on a semi-insulating GaAs (100) substrate by a Veeco Gen 930 solid-source molecular beam epitaxy (MBE). We used 20 periods of quantum cascade structures to enhance the light absorption. The conduction band diagram of one period of the QD-QCD is shown in Fig. 2. The detector was designed so as to detect infrared light peaks around $6 \mu \mathrm{m}$. The one-dimensional $\mathrm{k} \cdot \mathrm{p}$ method, with the SML-QDs layer replaced by InGaAs layer, was used to calculate the envelop wave function and energy level of the system ${ }^{17}{ }^{18}$. The active infrared absorption region was InAs/GaAs SML-QDs sandwiched by $1 \mathrm{~nm}$ GaAs on each side. The stacked SML-QDs layers consisted of five alternating layers of 0.57 ML InAs and 2.26 ML GaAs with n-doping density around $1 \times 10^{17} \mathrm{~cm}^{-3}$, which were deposited with $10 \mathrm{~s}$ interruption. The SML-QDs layers along with the following $1 \mathrm{~nm} \mathrm{GaAs}$ and $3 \mathrm{~nm} \mathrm{Al} \mathrm{n}_{0.3} \mathrm{Ga}_{0.7} \mathrm{As}$ layers were grown at $500{ }^{\circ} \mathrm{C}$. The two $\mathrm{In}_{0.2} \mathrm{Ga}_{0.8} \mathrm{As}$ quantum wells and their $\mathrm{Al}_{0.3} \mathrm{Ga}_{0.7} \mathrm{As}$ barriers were also grown at $500^{\circ} \mathrm{C}$. All the rest layers shown in Fig. 1 were grown at $580{ }^{\circ} \mathrm{C}$. The succeeding GaAs/AlGaAs/InGaAs quantum wells were carefully designed to form a LO-phonon energy stair between subsequent wells, which enabled an efficient extraction of the excited electrons. In order to minimize the cumulative compressive strain buildup, only two instead of five InGaAs well layers were used to design the cascade transport region in the device. The first three QWs of the stair QWs were based on $\mathrm{Al}_{0.3} \mathrm{Ga}_{0.7} \mathrm{As} / \mathrm{GaAs}$ materials without any strain. The fourth and fifth QWs were formed 
with $4 \mathrm{~nm} \mathrm{Al}_{0.3} \mathrm{Ga}_{0.7} \mathrm{As} / 3 \mathrm{~nm} \mathrm{In}{ }_{0.2} \mathrm{Ga}_{0.8} \mathrm{As}$ and $4 \mathrm{~nm} \mathrm{Al}_{0.3} \mathrm{Ga}_{0.7} \mathrm{As} / 4 \mathrm{~nm} \mathrm{In}_{0.2} \mathrm{Ga}_{0.8} \mathrm{As}$, respectively. Similar to Barve 's design, $50 \mathrm{~nm} \mathrm{Al}_{0.07} \mathrm{Ga}_{0.93} \mathrm{As}$ layer was grown between the active region and the $\mathrm{n}$-doped top and bottom contacts in order to minimize the tunneling injection of electron into the quantum dots from contacts ${ }^{11}$.

After material growth, the devices were processed into a set of mesa isolated photodetectors with device diameters ranging from $20 \mu \mathrm{m}$ to $500 \mu \mathrm{m}$, using standard methods of UV photolithography, wet etching, contacts metallization and lift-off. The dark current density-voltage characteristics of a device with $130 \mu \mathrm{m}$ diameter measured at various temperatures are shown in Fig 3. The device shows a dark current density of $1.57 \times 10^{-5} \mathrm{~A} / \mathrm{cm}^{2}$ at $300 \mathrm{~K}$ at $-0.1 \mathrm{~V}$, and decreases to $8.02 \times 10^{-9} \mathrm{~A} / \mathrm{cm}^{2}$ at 100 $\mathrm{K}$. It is noted that the dark current measured at $77 \mathrm{~K}$ shows a small photovoltaic shift, which is due to the imperfections in the cold shield used for the measurement. The dark current density demonstrated in this structure is much lower than that in the SK mode QD-QCD reported in Barve 's work ${ }^{11}$. Figure 4 shows the calculated temperature dependence of the resistance-area product $\left(\mathrm{R}_{0} \mathrm{~A}\right)$ for the same $130 \mu \mathrm{m}$ diameter device around zero bias. The $\mathrm{R}_{0} \mathrm{~A}$ value at $77 \mathrm{~K}$ is $1.54 \times 10^{8} \Omega \cdot \mathrm{cm}^{2}$ and decreases to $4163 \Omega \cdot \mathrm{cm}^{2}$ at $300 \mathrm{~K}$.

Spectral response of the QD-QCD device at different temperature was measured by the Fourier transform infrared spectrometer in the normal incidence configuration. Blackbody source at $700{ }^{\circ} \mathrm{C}$ with a chopper at a modulation frequency of $140 \mathrm{~Hz}$ was used to calibrate the responsivity of the photodetector. The responsivities of the device measured under zero bias at $77 \mathrm{~K}, 100 \mathrm{~K}$, and $130 \mathrm{~K}$ are shown in Fig 5. Peak responsivity around $6 \mu \mathrm{m}$ is $1.9 \mathrm{~mA} / \mathrm{W}, 1.13 \mathrm{~mA} / \mathrm{W}$ and $0.089 \mathrm{~mA} / \mathrm{W}$ at $77 \mathrm{~K}, 100 \mathrm{~K}$ and $130 \mathrm{~K}$, respectively. These values are comparable to the previously reported SK-grown QD-QCDs ${ }^{11,12}$.

The Johnson noise limited detectivity can be calculated by ${ }^{12}$ :

$$
D^{*}=R \sqrt{\frac{R_{0} A}{4 k_{B} T}}
$$

where $\mathrm{R}$ is the responsivity, $\mathrm{k}_{\mathrm{B}}$ is the Boltzmann constant, and $\mathrm{T}$ is the temperature. The Johnson noise limited detectivities of the QD-QCD at $77 \mathrm{~K}, 100 \mathrm{~K}$ and $130 \mathrm{~K}$ under zero bias are shown in Fig 6 . The corresponding peak value is $3.22 \times 10^{11}$ $\mathrm{cm} \cdot \mathrm{Hz}^{1 / 2} / \mathrm{W}, 1.01 \times 10^{11} \mathrm{~cm} \cdot \mathrm{Hz}^{1 / 2} / \mathrm{W}$ and $2.5 \times 10^{9} \mathrm{~cm} \cdot \mathrm{Hz}^{1 / 2} / \mathrm{W}$, respectively. The peak detectivity shown in Fig. 6 is higher than that of the SK-grown QD-QCD on GaAs shown in Barve's work ${ }^{11}$ and comparable to that of QD-QCD on InP in Wang's work 12. The high Johnson noise limited specific detectivity achieved in this quantum cascade structure is mainly due to the high $\mathrm{R}_{0} \mathrm{~A}$ and thus low Johnson noise. 
In conclusion, we reported a sub-monolayer quantum dot quantum cascade photodetector grown on GaAs substrate. Under zero bias, the Johnson noise limited detectivity at around $6 \mu \mathrm{m}$ is $2.5 \times 10^{9} \mathrm{~cm} \cdot \mathrm{Hz}^{1 / 2} / \mathrm{W}$ at $130 \mathrm{~K}$, and it increases to $3.22 \times 10^{11}$ $\mathrm{cm} \cdot \mathrm{Hz}^{1 / 2} / \mathrm{W}$ at $77 \mathrm{~K}$. These preliminary results show better performance than the quantum dot quantum cascade photodetector grown on GaAs by the traditional Stranski-Krastanov mode and are comparable to the devices grown on InP substrate, which is very promising for future low power dissipation and high performance focal plane array application.

This work is supported by Shanghai Sailing Program (17YF1429300); ShanghaiTech University startup funding (F-020316-002) and UK EPSRC First Grant (EP/R006172/1).

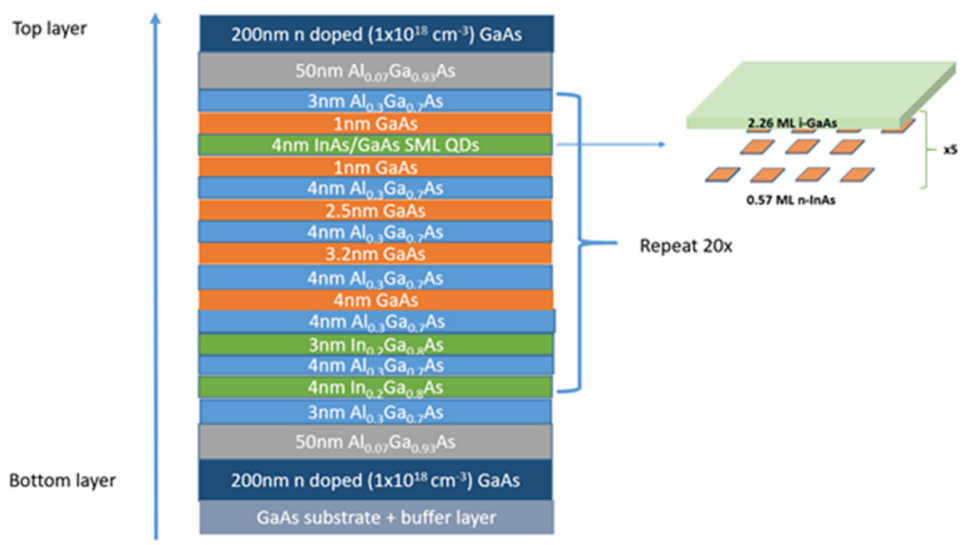

FIG. 1. Schematics of the device structure.

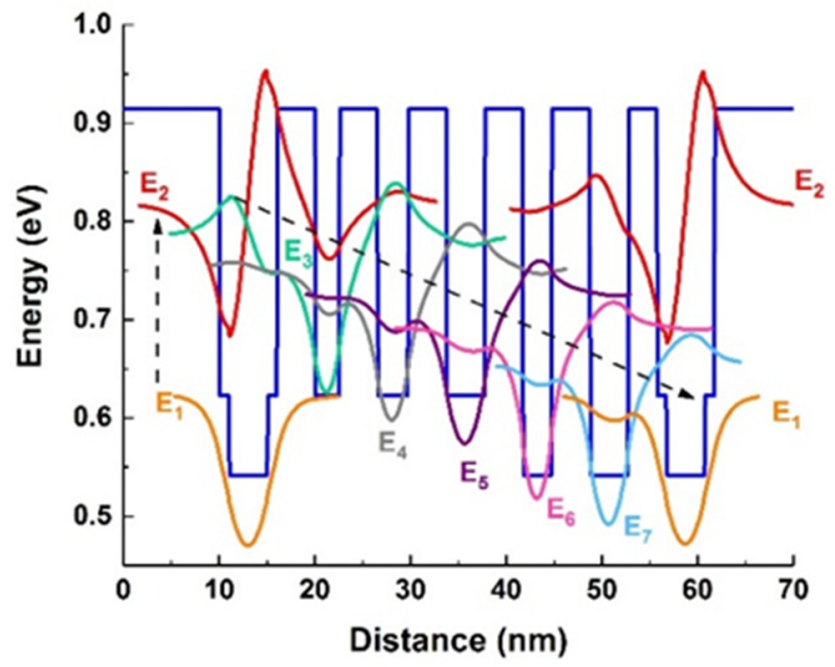

FIG. 2. Conduction band diagram of one period of the QD-QCD with calculated eigen-energies and wave functions shown. The layer sequence starting from the tunneling barrier is shown as follow (from left to right): $3 \mathrm{~nm}$ AlGaAs/1nm GaAs/4nm InGaAs (with SML QD 
layers)/1nm GaAs/4nm AlGaAs/2.5nm GaAs/4nm AlGaAs/3.2nm GaAs/4nm AlGaAs/4nm GaAs/4nm AlGaAs/3nm InGaAs/4nm AlGaAs/4nm InGaAs.

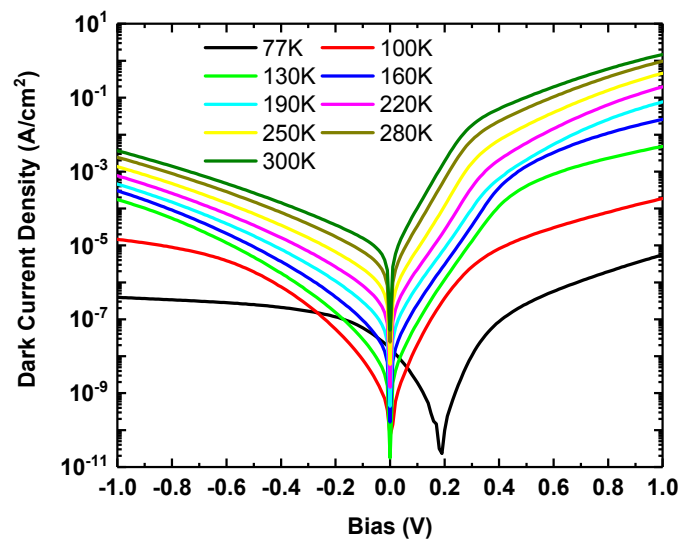

FIG. 3. Dark current density versus voltage for a $130 \mu \mathrm{m}$ QD-QCD device measured at temperature from $77 \mathrm{~K}$ to $300 \mathrm{~K}$.

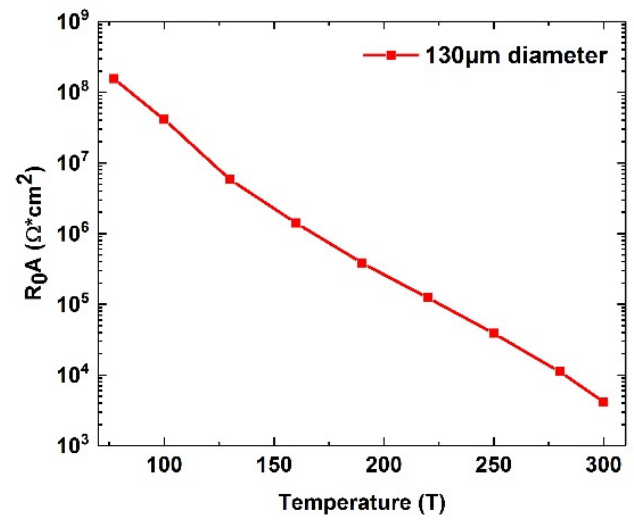

FIG. 4. Temperature dependence of R0A product for a $130 \mu \mathrm{m}$ QD-QCD device. 


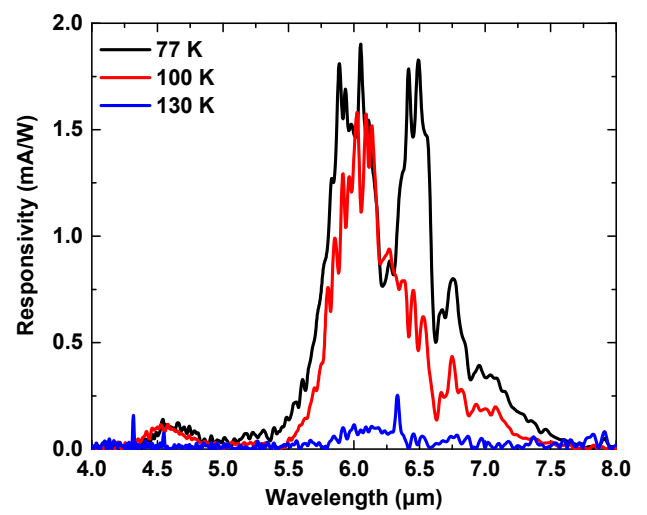

FIG. 5. Normal incident photoresponse of the QD-QCD measured at temperature of $77 \mathrm{~K}, 100 \mathrm{~K}$, and $130 \mathrm{~K}$ under zero bias.

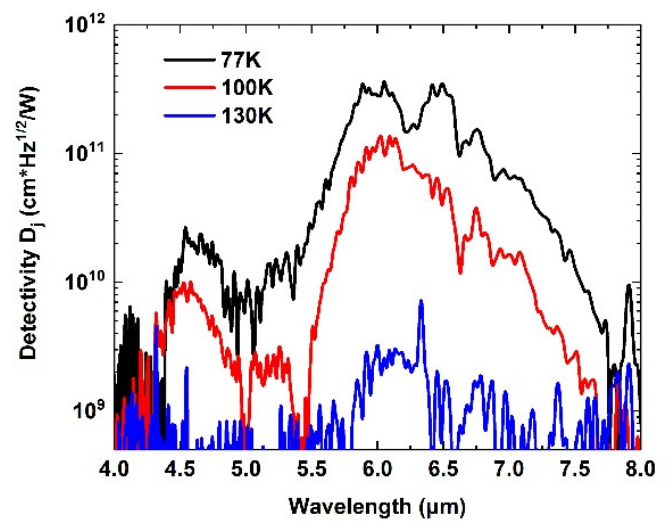

Fig. 6. The Johnson noise limited detectivity of the QD-QCD calculated at $77 \mathrm{~K}, 100 \mathrm{~K}$ and $130 \mathrm{~K}$ under zero bias.

1 Fabrizio R Giorgetta, Esther Baumann, Marcel Graf, Quankui Yang, Christian Manz, Klaus Kohler, Harvey E Beere, David A Ritchie, Edmund Linfield, and Alexander G Davies, IEEE Journal of Quantum Electronics 45 (8), 1039 (2009).

2 Fabrizio R Giorgetta, Esther Baumann, Daniel Hofstetter, Christian Manz, Quankui Yang, Klaus Köhler, and Marcel Graf, Applied Physics Letters 91 (11), 111115 (2007).

3 Marcel Graf, Nicolas Hoyler, Marcella Giovannini, Jérôme Faist, and Daniel Hofstetter, Applied physics letters 88 (24), 241118 (2006).

4 Daniel Hofstetter, Fabrizio R Giorgetta, Esther Baumann, Quankui Yang, Christian Manz, and Klaus Köhler, Applied Physics Letters 93 (22), 221106 (2008).

5 A Buffaz, M Carras, L Doyennette, A Nedelcu, X Marcadet, and V Berger, Applied Physics Letters 96 (17), 172101 (2010). 
Andreas Harrer, Benedikt Schwarz, Roman Gansch, Peter Reininger, Hermann Detz, Tobias Zederbauer, Aaron Maxwell Andrews, Werner Schrenk, and Gottfried Strasser, Applied Physics Letters 105 (17), 171112 (2014).

7

A Harrer, B Schwarz, S Schuler, P Reininger, A Wirthmüller, H Detz, D Macfarland, T Zederbauer, AM Andrews, and M Rothermund, Optics express 24 (15), 17041 (2016).

Peter Reininger, Benedikt Schwarz, Andreas Harrer, Tobias Zederbauer, Hermann Detz, Aaron Maxwell Andrews, Roman Gansch, Werner Schrenk, and Gottfried Strasser, Applied Physics Letters 103 (24), 241103 (2013).

AD Stiff, S Krishna, P Bhattacharya, and S Kennerly, Applied Physics Letters 79 (3), 421 (2001).

EA Zibik, Thomas Grange, BA Carpenter, NE Porter, R Ferreira, G Bastard, D Stehr, S Winnerl, M Helm, and HY Liu, Nature materials 8 (10), 803 (2009).

AV Barve and S Krishna, Applied Physics Letters 100 (2), 021105 (2012).

Xue-Jiao Wang, Shen-Qiang Zhai, Ning Zhuo, Jun-Qi Liu, Feng-Qi Liu, Shu-Man Liu, and Zhan-Guo Wang, Applied Physics Letters 104 (17), 171108 (2014).

Zhangcheng Xu, Kristjan Leosson, Dan Birkedal, Vadim Lyssenko, Jørn M Hvam, and Janusz Sadowski, Nanotechnology 14 (12), 1259 (2003).

F Hopfer, A Mutig, M Kuntz, G Fiol, D Bimberg, NN Ledentsov, VA Shchukin, SS Mikhrin, DL Livshits, and IL Krestnikov, Applied physics letters 89 (14), 141106 (2006).

Phu Lam, Jiang Wu, Mingchu Tang, Qi Jiang, Sabina Hatch, Richard Beanland, James Wilson, Rebecca Allison, and Huiyun Liu, Solar energy materials and solar cells 126, 83 (2014). David Z-Y Ting, Sumith V Bandara, Sarath D Gunapala, Jason M Mumolo, Sam A Keo, Cory J Hill, John K Liu, Edward R Blazejewski, Sir B Rafol, and Yia-Chung Chang, Applied Physics Letters 94 (11), 111107 (2009).

Baile Chen, IEEE Transactions on Electron Devices 64 (4), 1606 (2017).

Baile Chen, Optics Express 25 (21), 25183 (2017). 
$200 \mathrm{~nm} \mathrm{n}$ doped $\left(1 \times 10^{18} \mathrm{~cm}^{-3}\right) \mathrm{GaAs}$

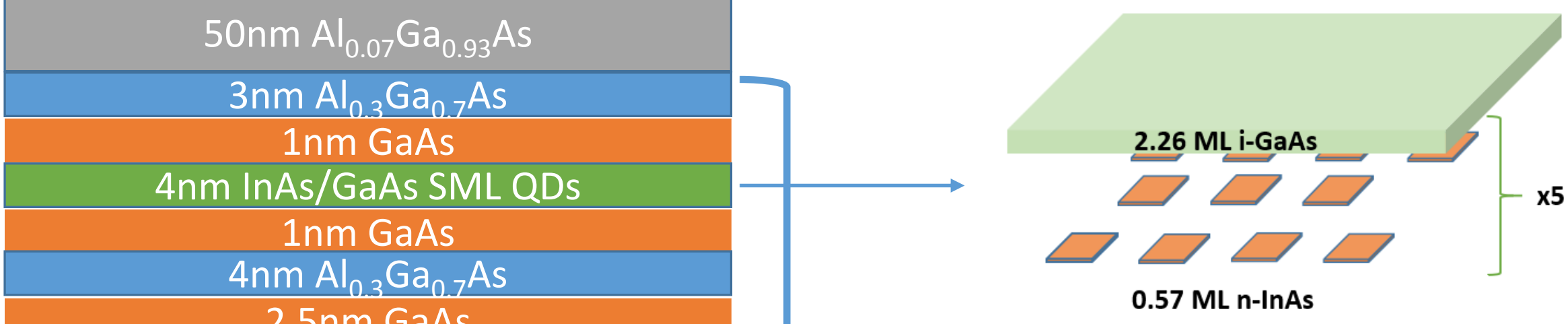

$2.5 \mathrm{~nm} \mathrm{GaAs}$

$4 \mathrm{~nm} \mathrm{Al}{ }_{0.3} \mathrm{Ga}_{0.7} \mathrm{As}$

$3.2 n m$ GaAs

$4 \mathrm{~nm} \mathrm{Al}{ }_{0.3} \mathrm{Ga}_{0.7} \mathrm{As}$

$4 n m$ GaAs

$4 \mathrm{~nm} \mathrm{Al} \mathrm{O}_{0.3} \mathrm{Ga}_{0.7} \mathrm{As}$

$3 \mathrm{~nm} \ln _{0,2} \mathrm{Ga}_{0.8}$ As

$4 n m \mathrm{Al}_{n_{2}} \mathrm{Ga}_{\mathrm{n}_{7}} \mathrm{As}$

$4 \mathrm{~nm} \operatorname{In}_{0,2} \mathrm{Ga}_{0.8} \mathrm{As}$

$3 \mathrm{~nm} \mathrm{Al}{ }_{0.3} \mathrm{Ga}_{0.7} \mathrm{As}$

$50 \mathrm{~nm} \mathrm{Al} \mathrm{l}_{0.07} \mathrm{Ga}_{0.93} \mathrm{As}$
Repeat 20x

GaAs substrate + buffer layer 


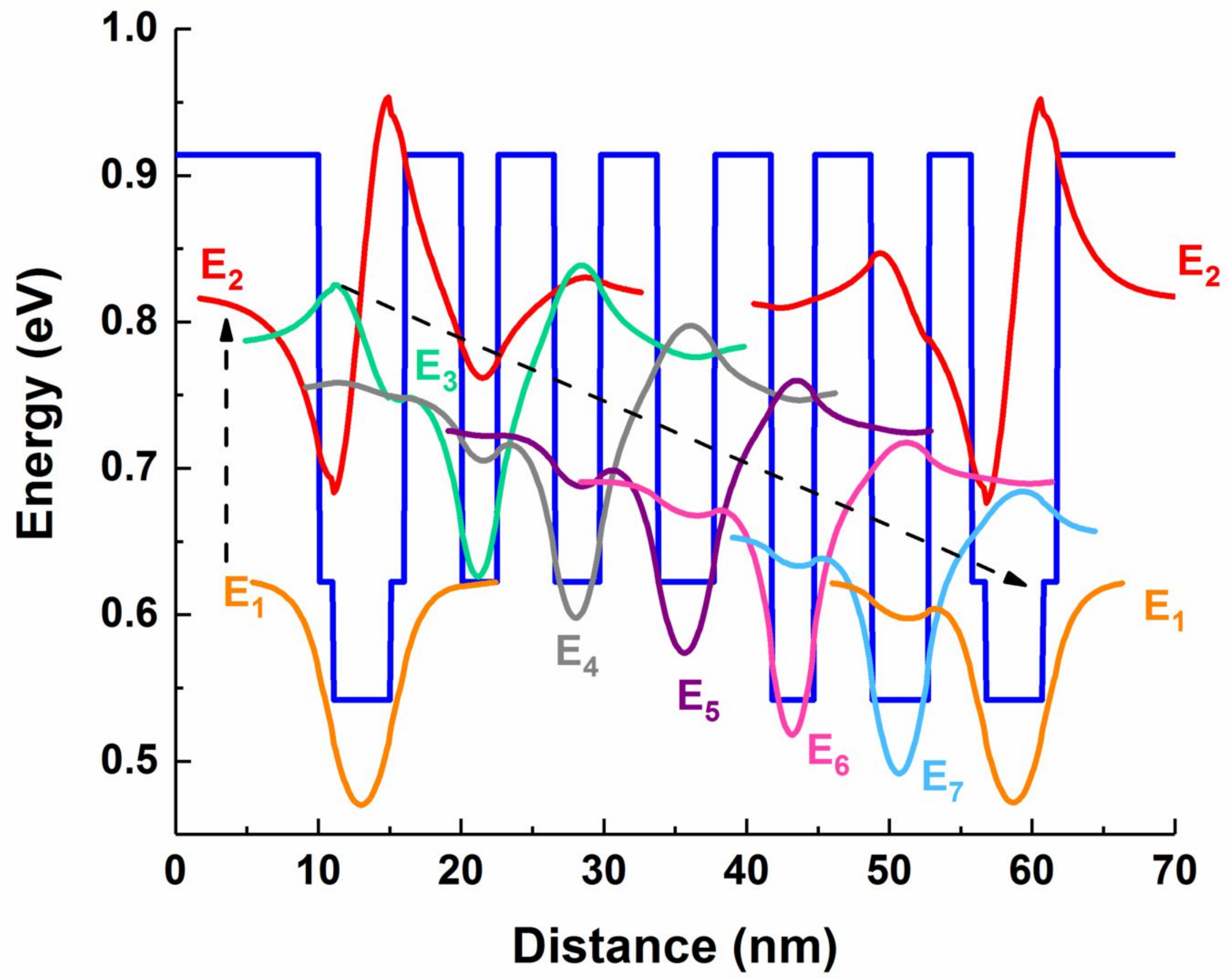




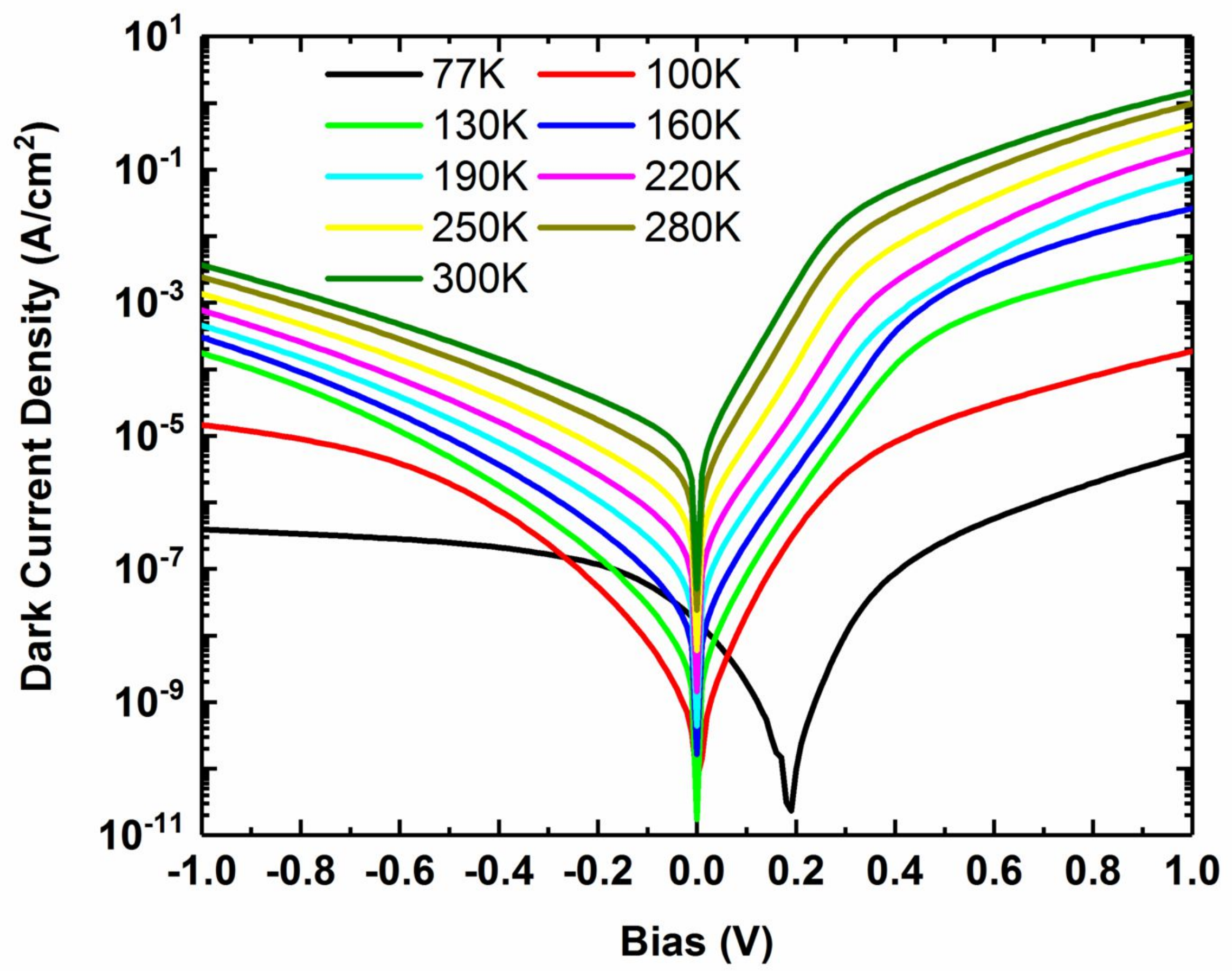




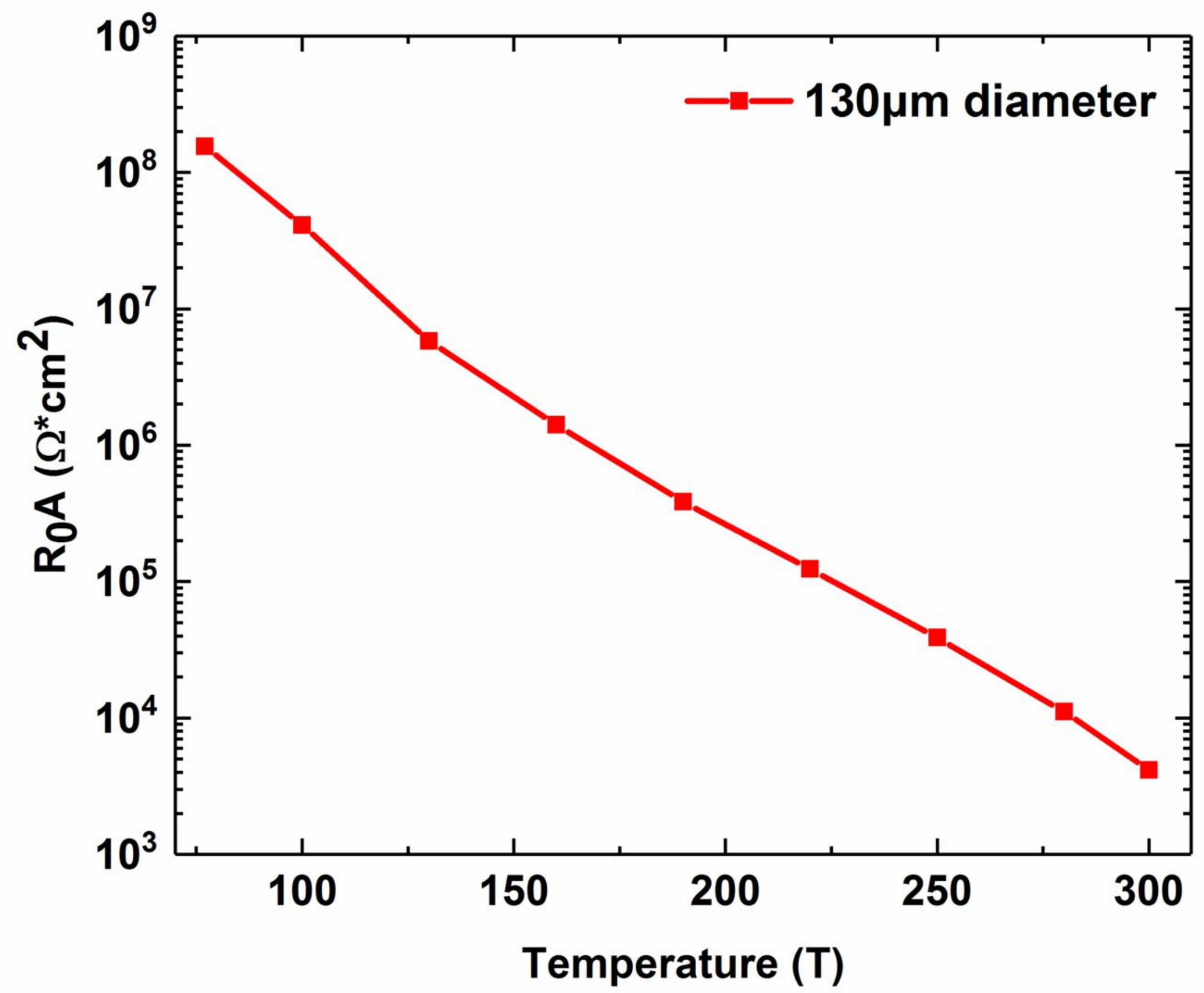




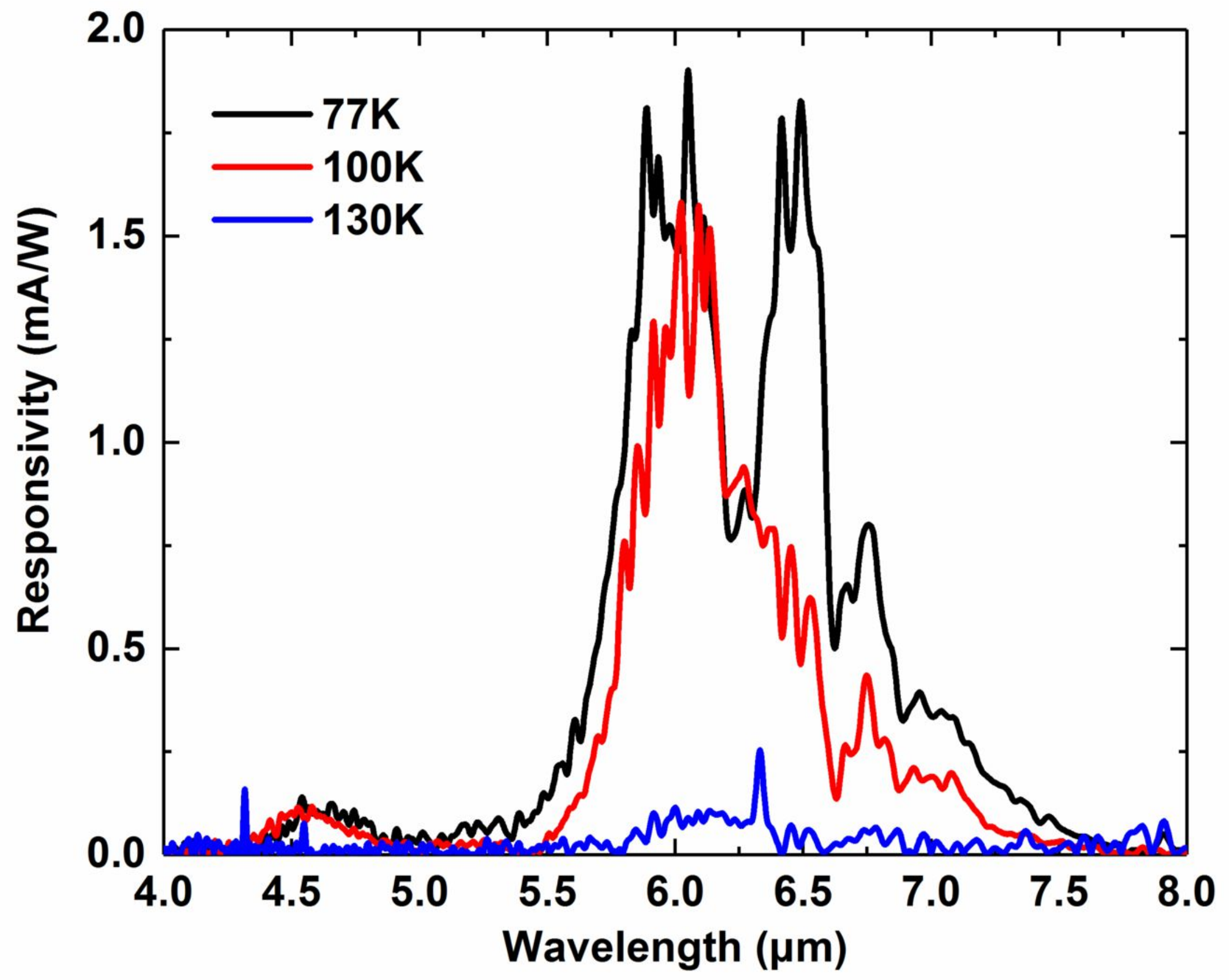




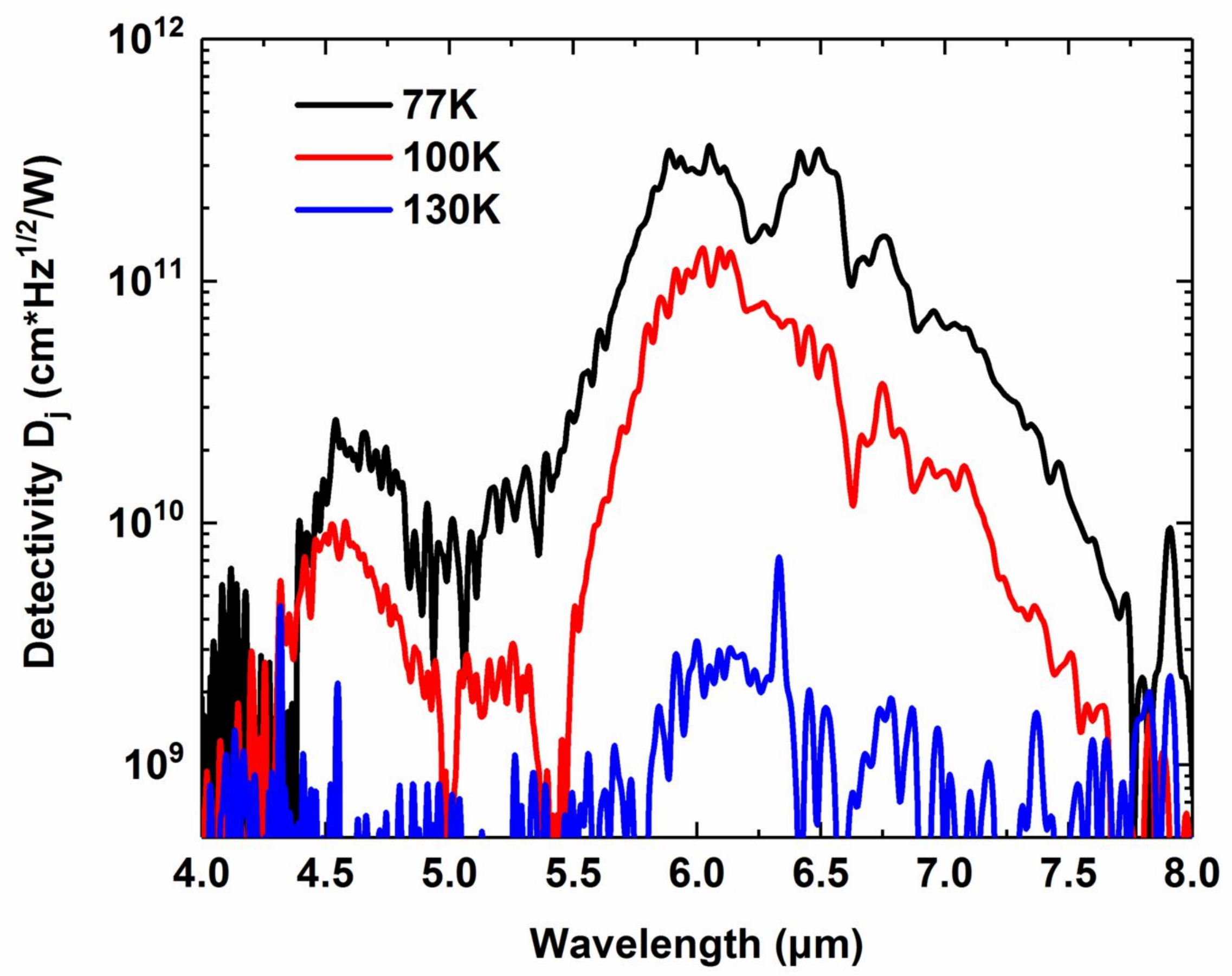

